\title{
Procalcitonin as a marker of infection in febrile neutropenia: A systematic review
}

\author{
Anders K. Boysen ${ }^{1,2^{\star}}$, Bettina R. Jensen ${ }^{1}$, Laurids $\varnothing$. Poulsen ${ }^{2}$, Paw Jensen ${ }^{3}$, \\ Søren Ladefoged ${ }^{4}$ \\ ${ }^{1}$ Department of Oncology, Aarhus University Hospital, Aarhus , Denmark; ${ }^{2}$ Corresponding Author: ankib@,rn.dk \\ ${ }^{2}$ Department of Oncology, Aalborg University Hospital, Aalborg, Denmark \\ ${ }^{3}$ Department of Hematology, Aalborg University Hospital, Aalborg, Denmark \\ ${ }^{4}$ Department of Clinical Biochemistry, Aarhus University Hospital, Aarhus, Denmark
}

Received 14 November 2012; revised 19 December 2012; accepted 17 January 2013

\begin{abstract}
Aim: Management of febrile neutropenia is challenged by lacking microbiological and clinical documentation of infection. Procalcitonin is emerging as a new promising biomarker of infection. We aimed to undertake a systematic review evaluating the diagnostic accuracy of procalcitonin as a marker of infection in febrile neutropenia. Methods: We performed a systematic review of the literature using the databases MEDLINE, EMBASE and Cochrane Library including a search of the grey literature (e.g. unpublished data, web sides of relevant societies). The methodological quality was assessed using predefined criteria. The relevant data were extracted and analyzed by two authors. Results: The literature search yielded a total of 193 studies of which nine were eligible for inclusion. There was a great variation in the quality of the methodological design. A notable heterogeneity exists regarding the studied populations and the definition of the reference standards. Among the nine included studies the sensitivity ranged from $42 \%$ to $72 \%$ and the specificity ranged from $64 \%$ - $89 \%$ at a cut off value ranging from $0.5-0.8$ $\mathrm{ng} / \mathrm{ml}$. The studied endpoint was either microbiologically or clinically documented infection. Four studies found procalcitonin superior to C-reactive protein in discriminating infection from the various other causes of fever. Conclusion: Procalcitonin appears to be a promising biomarker and might add new diagnostic information in the management of febrile neutropenia.
\end{abstract}

Keywords: Procalcitonin; Febrile Neutropenia

\section{INTRODUCTION}

Procalcitonin (PCT) is the precursor molecule of the calcium regulating hormone calcitonin, consisting of 116 amino acids and encoded by the CALC-1 gene on chromosome 11 [1]. In healthy individuals PCT is cleaved to the biologically active hormone calcitonin in the C-cells of the thyroid gland and the amount of intact PCT released to the bloodstream is usually below the detection limit. Following a stimulus of bacterial endotoxins induction extrathyroid of PCT synthesis has been reported. Multiple tissues are considered as sites of production, e.g. liver and neuroendocrine cells in the lungs [2]. PCT shows a favorable kinetic profile as a biomarker for infections with a rapid rise peaking after 6 hours, a plateau phase up to 24 hours and normalizing within 2 - 3 days, while C-reactive protein (CRP) may take up to 24 hours to peak and a plateau phase for several days followed by a slow normalizing $[3,4]$.

Elevated levels of PCT in patients with sepsis and infection were first described in 1993 by Assicot and colleagues [5]. Within the last decades PCT has emerged as a promising marker of infection with a proposed higher sensitivity and specificity than traditional markers such as CRP [6]. The recent results have been conflicting with a meta-analysis from 2004 [7] demonstrating superior diagnostic accuracy of PCT compared to CRP in the dia-gnosis of bacterial infections in a mixed adult and pediatric population, while a second meta-analysis from 2007 [8] examined the utility of PCT in critically ill patients and concluded that the diagnostic performance of PCT in discriminating sepsis from non-infectious causes of systemic inflammatory response syndrome (SIRS) was low.

PCT has been studied in immunocompromized patients with sepsis, first by Al-Nawas in 1996 [9] studying 55 patients with various causes of immunosuppression, e.g. hematological malignancies, chemotherapy induced neutropenia, HIV infection and following organ transplantation. They found a similar increase of PCT at the onset of sepsis compared to a group of controls with normal immune system. 
Febrile neutropenia (FN) is a frequent complication following chemotherapy in hematological and oncologycal patients. $\mathrm{FN}$ is often defined by a temperature $>$ $38.5^{\circ} \mathrm{C}$ for $1 \mathrm{~h}$ and an absolute neutrophil count $<0.5 \times$ $10^{9} / \mathrm{L}$. It is a potentially life threatening condition with a mortality rate of $5 \%$ in patients with solid tumors and up to $10 \%$ in hematological malignancies [10]. Additionally, FN might have adverse affect on the overall treatment outcome due to dose reductions, treatment delays or chemotherapy discontinuation, especially in the adjuvant setting [11,12]. Management of FN is challenging due to a often lack of a clear focus of infection during physical examination [13] and a low diagnostic accuracy of the well established markers of infection (e.g. CRP) to discriminate between infection and the various other causes of fever in the adult cancer patient [14]. The most accurate way to diagnose bacterial infections is by culture [7] but the result is delayed and the incidence of bacteremia in $\mathrm{FN}$ is low, e.g. $10 \%-20 \%[15,16]$.

PCT has been considered as a new specific marker of infection in FN. A review of the existing literature was performed in 2008 by Sakr and colleagues [17] who reviewed the literature for both adult and children includeing patients treated with high dose chemotherapy and stem cell transplantation. They concluded that PCT might be useful as a diagnostic tool in FN but due to heterogeneity no objective parameters regarding the diagnostic accuracy of PCT are available for the adult cancer patient treated with standard-dose cancer therapy. The aim of this systematic review is to identify, critically appraise and qualitative synthesize the current literature examining the diagnostic accuracy of PCT as a marker of infection in adult cancer patients presenting with FN.

\section{METHODS}

\subsection{Literature Search}

A systematic search of literature was performed in January 2012 including published papers from 1990 to 2011. The electronic databases MEDLINE, EMBASE and Cochrane library were used using the search terms: "Procalcitonin", "Febrile neutropenia" and "immunosuppression". Both free text and medical subject headings $(\mathrm{MeSH})$ search were applied and no limitations in regard to language were used. Both observational and interventional studies were eligible for inclusion. The references of the retrieved studies were further cross-checked for potential studies missed in the electronic databases. The websites for conferences and relevant societies were examined for unpublished data and abstracts (e.g. American Society of Clinical Oncology, International Society for Infectious Disease, and American Association for Clinical Chemistry).

\subsection{Study Selection and Inclusion Criteria}

Two investigators (AKB and BRJ) independently performed the search and selection by initially screening the title and abstract for relevance and excluding duplicates. In the next step the relevant studies were retrieved in full text and carefully assessed in the relation to predefined inclusion and exclusion criteria before submission to data extraction. The inclusion criteria were:

1) Clinical studies evaluating the diagnostic accuracy of PCT as a marker of infection in adult patients with FN. The diagnostic accuracy must be expressed explicitly as sensitivity and specificity or presenting data making it possible for the investigators to calculate these parameters.

2) The presence of either a hematological malignancy or a solid tumor and relevant oncological treatment as the cause of neutropenia.

3) Studies examining either clinically or microbiologically documented infection as an endpoint

Exclusion criteria were:

1) Studies evaluating patients treated with either autologous or allogenic stem cell transplantation

2) A pediatric study population (age $<16 \mathrm{y}$ )

3) Other causes of immunosuppresion, e.g. HIV, organ transplantation in the study population

Any disagreements between the authors were resolved by consensus.

\subsection{Data Extraction and Quality Assessment}

The following data were extracted from the included studies: Name of first author and year of publication, number of patients and FN episodes, patient population evaluated, study design, endpoint and the diagnostic accuracy of PCT as a marker of bacterial infection. A quality assessment of all included studies was performed using the QUADAS-2 (Quality Assessment of Diagnostic Accuracy Studies) tool published in a revised version in 2011 [18]. The QUADAS-2 tool examines four domains for risk of bias: 1) patient selection, 2) index test, 3 ) reference test; and 4) flow and timing. The first three domains are also assessed in terms of concern of applicability. Using this tool the risk of bias is classified as either "high", "low" or "unclear" for each domain.

To support the judgment of risk of bias, two authors (AKB and BRJ) employed specific signaling questions to each domain which could be answered "yes", "no" or "unclear". If all signaling questions are answered yes the risk of bias is judge as being low. If any signaling question is answered "no", a risk of bias exists. As recommended by the QUADAS-2 guidelines [18] the applied signaling questions has been tailored to the current review and are displayed in Figure 1. 


Domain 1
1) Was a consecutive or random sample of
patients enrolled?
2) Was a case-control design avoided?
3) Did the study avoid inappropriate exclusions?
Domain 2
1) Did the study clearly state how PCT measurement was
performed?
2) Was the threshold prespecified
Domain 3
1) Was the reference standard likely to correctly classify the target
condition?
2) Did the study present objective criterias for the definition of
clinically documented infection?
3) Did the study define which microbiologically cultures are
considered "documented infection"?
4) Was the reference standard interpreted without knowledge of the
index test?
Domain 4
1) Was there an appropriate interval between the index test and the
reference standard?
2) Did all patients receive the same reference standard?
3) Were all patients included in the analysis?

Figure 1. Signaling questions for quality assessment.

\section{RESULTS}

The literature search in the electronic databases

EMBASE, PubMed and the Cochrane Library along side the manuel crosscheck of the bibliographies yielded a total of 193 studies of potential interest. Following removal of duplicates and screening title and abstract for relevance 35 studies remained eligible for inclusion. After full text review 9 articles were included. The main reasons for exclusion were a pediatric study population, studies evaluating bone marrow transplantation or insufficient data reported. A flowchart depicting the process of study selection is presented in Figure 2.

The 9 included studies are presented in Table 1 with the relevant data extracted [19-27]. Overall, a total of 1.498 episodes of FN in 1.396 patients were available for qualitative analysis. Five studies $[19,20,23,24,26]$ exclusively involved patients with hematological malignancies while only one study [22] examined patients with purely solid tumors. The remaining included a mixed onco-hematological population. The measured outcomes were in most cases either microbiologically (MDI) or clinically documented infection (CDI), three studies only had the presence of bacteremia as an endpoint $[21,25,27]$. Regarding the diagnostic accuracy of PCT, the sensitivity ranged from $42 \%$ to $72 \%$ and the specificity ranged from $64 \%-89 \%$. Seven studies furthermore described the positive predictive value (PPV) ranging from $28 \%-87 \%$ and six studies also included the negative predictive value (NPV) ranging from 19\% - 95\%.

PCT has been evaluated in relation to the infectious agent in three studies $[19,20,23]$. All found significantly

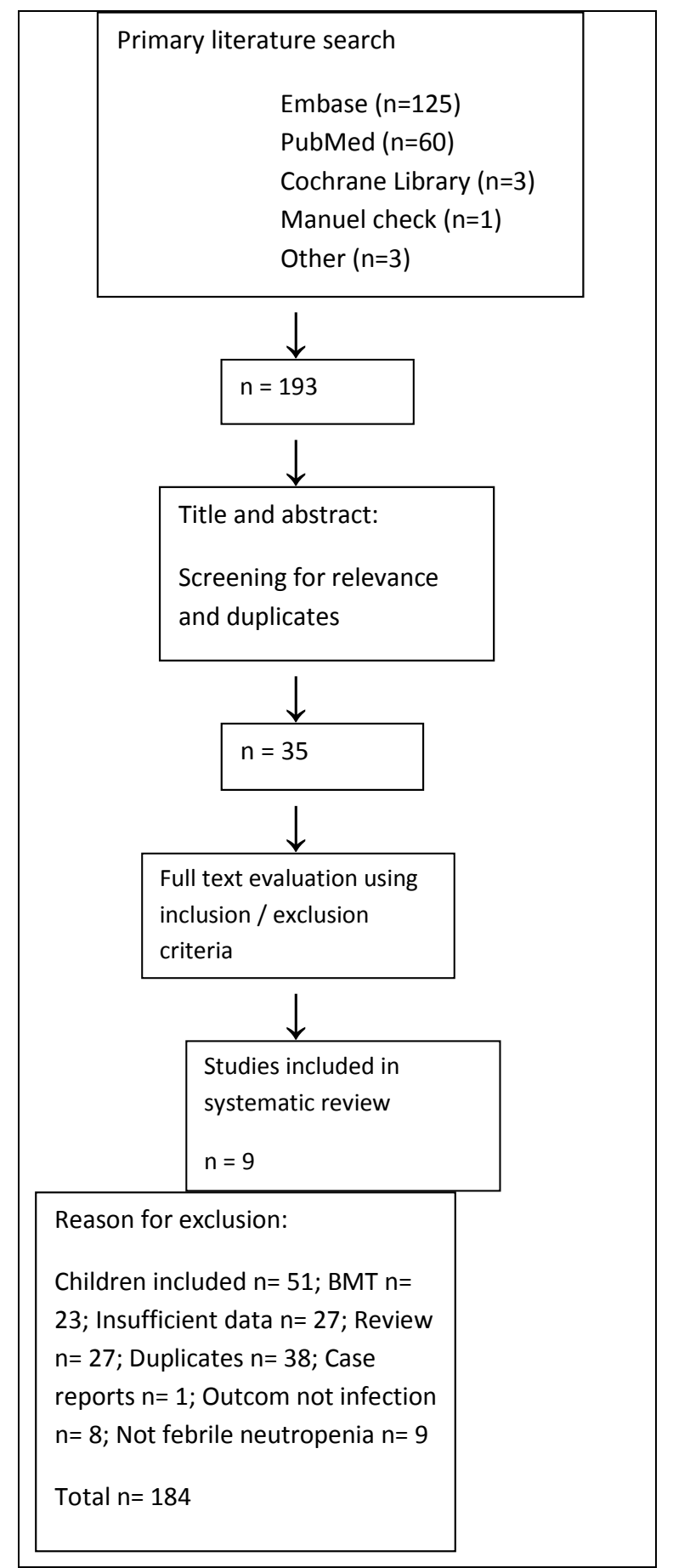

Figure 2. Flow diagram of study selection proces. BMT: bone marrow transplantation.

higher PCT levels in cases of Gram-negative bacteremia compared to all other episodes. Few data regarding PCT and systemic mycosis are available from the included trials, 5 cases of fungemia are reported by Giamarellou et al. [23] and a low level of PCT occurred in all patients. PCT has been examined as a marker of the severity of the infectious episode and data are presented in three stu- 
Table 1. Included studies reporting the diagnostic accuracy of PCT.

\begin{tabular}{|c|c|c|c|c|c|c|}
\hline $\begin{array}{l}\text { Study \# } \\
\text { [ref.] }\end{array}$ & Name of first author & $\begin{array}{c}\text { Number of FN } \\
\text { episodes (patients) }\end{array}$ & $\begin{array}{l}\text { Patient population } \\
\text { evaluated }\end{array}$ & $\begin{array}{c}\text { Year } \\
\text { of publication }\end{array}$ & Endpoint & $\begin{array}{l}\text { Diagnostic accuracy of PCT as a } \\
\text { marker of infection }\end{array}$ \\
\hline $\begin{array}{c}1 \\
{[19]}\end{array}$ & E. Ruokonen & $\begin{array}{c}28 \\
(28)\end{array}$ & $\begin{array}{l}\text { Hematological } \\
\text { malignacies }\end{array}$ & 1999 & $\begin{array}{l}\text { MDI } \\
\text { CDI }\end{array}$ & $\begin{array}{l}\text { Sen: } 55 \% \text {, Spe: } 88 \% \\
\text { PPV: NA, NPV: NA }\end{array}$ \\
\hline $\begin{array}{c}2 \\
{[20]}\end{array}$ & A. Engel & $\begin{array}{l}103 \\
(69)\end{array}$ & $\begin{array}{l}\text { Hematological } \\
\text { malignacies }\end{array}$ & 1999 & $\begin{array}{l}\text { MDI } \\
\text { CDI }\end{array}$ & $\begin{array}{l}\text { Sen: } 51 \% \text {, Spe: } 89 \% \\
\text { PPV: } 87 \% \text {, NPV } 57 \%\end{array}$ \\
\hline $\begin{array}{c}3 \\
{[21]}\end{array}$ & $\begin{array}{l}\text { E. Giamarellos- } \\
\text { Bouboulis }\end{array}$ & $\begin{array}{c}115 \\
(115)\end{array}$ & $\begin{array}{l}\text { Hematological } \\
\text { malignacies } \\
\text { Solid tumors }\end{array}$ & 2001 & Bacteremia & $\begin{array}{l}\text { Sen: } 79 \% \text {, Spe: } 64 \% \\
\text { PPV: } 85 \% \text {, NPV: NA }\end{array}$ \\
\hline $\begin{array}{c}4 \\
{[22]}\end{array}$ & A. Jimeno & $\begin{array}{c}104 \\
(104)\end{array}$ & Solid tumors & 2003 & $\begin{array}{l}\text { MDI } \\
\text { CDI }\end{array}$ & $\begin{array}{l}\text { Sen: } 67 \% \text {, Spe: } 87 \% \\
\text { PPV: } 46 \% \text {, NPV } 94 \%\end{array}$ \\
\hline $\begin{array}{c}5 \\
{[23]}\end{array}$ & H. Giamarellou & $\begin{array}{c}158 \\
(158)\end{array}$ & $\begin{array}{l}\text { Hematological } \\
\text { malignacies }\end{array}$ & 2004 & $\begin{array}{l}\text { MDI } \\
\text { CDI }\end{array}$ & $\begin{array}{l}\text { Sen: } 42 \%, \text { Spe: } 64 \% \\
\text { PPV: } 82 \% \text {, NPV } 19 \%\end{array}$ \\
\hline $\begin{array}{c}6 \\
{[24]}\end{array}$ & M. von Lilienfeld-Toal & $\begin{array}{c}53 \\
(31)\end{array}$ & $\begin{array}{l}\text { Hematological } \\
\text { malignacies }\end{array}$ & 2004 & $\begin{array}{l}\text { MDI } \\
\text { CDI }\end{array}$ & $\begin{array}{l}\text { Sen: } 72 \% \text {, Spe: } 77 \% \\
\text { PPV: } 62 \% \text {, NPV } 84 \%\end{array}$ \\
\hline $\begin{array}{c}7 \\
{[25]}\end{array}$ & S. Ahn & $\begin{array}{l}285 \\
(249)\end{array}$ & $\begin{array}{l}\text { Hematological } \\
\text { malignacies } \\
\text { Solid tumors }\end{array}$ & 2011 & Bacteremia & $\begin{array}{l}\text { Sen: } 58 \%, \text { Spe: } 88 \% \\
\text { PPV: } 28 \%, \text { NPV } 96 \%\end{array}$ \\
\hline $\begin{array}{c}8 \\
{[26]}\end{array}$ & A.-C. Gac & $\begin{array}{c}39 \\
(29)\end{array}$ & $\begin{array}{l}\text { Hematological } \\
\text { malignancies }\end{array}$ & 2011 & $\begin{array}{l}\text { MDI } \\
\text { CDI }\end{array}$ & $\begin{array}{l}\text { Sen: } 60 \% \text {, Spe: } 82 \% \\
\text { PPV: } 54 \% \text {, NPV } 86 \%\end{array}$ \\
\hline $\begin{array}{c}9 \\
{[27]}\end{array}$ & D. Y. Kim & 286 & $\begin{array}{l}\text { Hematological } \\
\text { malignacies } \\
\text { Solid tumors }\end{array}$ & 2011 & Bacteremia & $\begin{array}{l}\text { Sen: } 61 \% \text {, Spe: } 82 \% \\
\text { PPV: NA, NPV NA }\end{array}$ \\
\hline
\end{tabular}

FN: Febrile neutropenia, MDI: microbiologically documented infection, CDI: clinically documented infection, Sen: sensitivity, Spe: specificity, PPV: positive predictive value, NPV: negative predictive value, NA: not available.

dies $[21,23,25]$. Giamarellos-Bourboulis et al. [21] found significant higher levels of PCT in patients with severe sepsis (defined as sepsis associated with organ dysfunction) compared to patients with a localized clinical infection. At a cut off value of $2 \mathrm{ng} / \mathrm{mL}$ PCT showed a high diagnostic accuracy with a sensitivity, specificity and positive predictive value of $91 \%, 87 \%$ and $77 \%$ for the diagnosis of severe sepsis.

The results of the quality assessments using the QUADAS- 2 tool are presented in Table 2. As shown, no study is without any risk of bias, and a marked difference in the methodological quality between the studies exists. The most frequent deficiencies in the design of the studies were inconsistencies in an objective definition of the reference standard (e.g. when was a positive blood culture for coagulase negative staphylococci considered infection?), failure to report whether the reference standard was interpreted blinded to the index test and a lack of information whether a consecutive or random sample of patients were enrolled. In concerning the domain of the index test only one study [21] was of low risk of bias due to the remaining studies not reporting a prespecified threshold for the PCT test. In diagnostic accuracy tests it might overestimate test performance if the cut-off value is selected to optimize sensitivity or specificity [18]. Two studies $[25,27]$ fail to report the laboratory technique for PCT measurement while the remaining used a quantitative immunoassay and the chosen cut off values ranged from $0.5-0.8 \mathrm{ng} / \mathrm{mL}$.
Table 2. Results of the quality assessment applied by the QUADAS tool [18].

\begin{tabular}{|c|c|c|c|c|c|c|c|}
\hline $\begin{array}{c}\text { Study } \\
\#\end{array}$ & $\begin{array}{c}\text { Patient } \\
\text { selection }\end{array}$ & $\begin{array}{c}\text { Index } \\
\text { test }\end{array}$ & $\begin{array}{l}\text { Reference } \\
\text { standard }\end{array}$ & $\begin{array}{l}\text { Flow } \\
\text { and } \\
\text { timing }\end{array}$ & $\begin{array}{c}\text { Patient } \\
\text { selection }\end{array}$ & $\begin{array}{c}\text { Index } \\
\text { test }\end{array}$ & $\begin{array}{c}\text { Reference } \\
\text { standard }\end{array}$ \\
\hline 1 & $\mathrm{~L}$ & $\mathrm{H}$ & $\mathrm{H}$ & $\mathrm{L}$ & $\mathrm{L}$ & $\mathrm{L}$ & $\mathrm{L}$ \\
\hline 2 & $\mathrm{~L}$ & $\mathrm{H}$ & $\mathrm{L}$ & $\mathrm{L}$ & $\mathrm{L}$ & $\mathrm{L}$ & $\mathrm{L}$ \\
\hline 3 & $\mathrm{H}$ & $\mathrm{L}$ & $\mathrm{H}$ & $\mathrm{L}$ & $\mathrm{L}$ & $\mathrm{L}$ & $\mathrm{H}$ \\
\hline 4 & $\mathrm{H}$ & $\mathrm{U}$ & $\mathrm{H}$ & $\mathrm{L}$ & $\mathrm{L}$ & $\mathrm{L}$ & $\mathrm{L}$ \\
\hline 5 & $\mathrm{H}$ & $\mathrm{L}$ & $\mathrm{H}$ & $\mathrm{H}$ & $\mathrm{L}$ & $\mathrm{L}$ & $\mathrm{L}$ \\
\hline 6 & $\mathrm{H}$ & $\mathrm{U}$ & $\mathrm{H}$ & $\mathrm{L}$ & $\mathrm{L}$ & $\mathrm{L}$ & $\mathrm{L}$ \\
\hline 7 & $\mathrm{~L}$ & $\mathrm{H}$ & $\mathrm{H}$ & $\mathrm{L}$ & $\mathrm{H}$ & $\mathrm{H}$ & $\mathrm{H}$ \\
\hline 8 & $\mathrm{H}$ & $\mathrm{H}$ & $\mathrm{H}$ & $\mathrm{H}$ & $\mathrm{H}$ & $\mathrm{H}$ & $\mathrm{H}$ \\
\hline 9 & $\mathrm{~L}$ & $\mathrm{~L}$ & $\mathrm{~L}$ & $\mathrm{~L}$ & $\mathrm{~L}$ & $\mathrm{~L}$ & $\mathrm{~L}$ \\
\hline 10 & $\mathrm{H}$ & $\mathrm{H}$ & $\mathrm{H}$ & $\mathrm{L}$ & $\mathrm{L}$ & $\mathrm{U}$ & $\mathrm{H}$ \\
\hline
\end{tabular}

H: high risk, L: low risk, U: unknow.

\section{DISCUSSION}

Management of FN remains a major clinical problem for physicians working in fields of oncology or malignant hematological diseases. At present, the patient with FN is handled with a careful history and clinical exam followed by laboratory evaluation including measurement of CRP, chest x-ray and microbiological cultures. Prompt initiation of broad-spectrum antibiotic therapy is warranted due to the risk of rapid deterioration in case of 
bacteremia $[28,29]$. PCT has been proposed as a new biomarker of infection with higher specificity in discriminating infection from the various other causes of fever in this population, e.g. drug fever, administration of blood products, paraneoplastic fever [30]. We undertook a qualitative systematic review and found only 9 studies describeing the diagnostic accuracy of PCT as a marker of infection in the adult cancer patient presenting with FN following treatment with standard chemotherapy regimens. Our results indicate that PCT has a relatively high specificity ranging from $64 \%-89 \%$ but only an intermediate sensitivity ranging from $42 \%-72 \%$ at a threshold of $0.5-0.8 \mathrm{ng} / \mathrm{mL}$, thus suggesting a potential role for PCT as a more specific biomarker and supplementing the current approach to FN. Four of the included studies compare the diagnostic value of PCT to CRP and all found PCT to be superior to CRP [23-25,27].

Results from systematic reviews are often limited due to heterogeneity of the included trials in design, methodology and population.

Despite applying quite strict criteria for inclusion, our synthesis also demonstrates differences among the included trials. The studied population included both patient with solid tumors and hematological malignancies. Previous studies have shown that FN has a different natural history in hematological neoplasms with a higher mortality rate and higher incidence of bacteremia and opportunistic infections [31]. The study by Ahn and collegues [24] evaluated only patients in low-risk of com- plications and mortality as defined by the risk index of the Multinational Association for Supportive Care in Cancer (MASCC) [32], thus selecting patients with minimal comorbidity and low tumor burden. Attempting to increase the applicability of our results to what is seen at a major departments of oncology, we excluded the most profound immunosuppresed hematological patients treated with bone marrow transplantation.

Most of the included studies presented similar challenges in reporting objective definitions for allocating patients to either infection or fever of other cause and whether this was done blinded to the value of the index test. Only the trial by Ruokonen and colleageus [19] describes the minimum of colonies required in a urinary culture in order to classify the condition as a urinary tract infection. Seven studies [19,20,22-26] report predefined criteria for the diagnosis of coagulase negative staphulococcal bacteremia in discriminating this from contamination. In general, the included studies scored quite low (e.g. high risk of bias) when appraised by the QUADAS2 tool especially involving the domains of patient selection, index test and reference standard. The domain of flow and timing was generally judged to be less biased, and overall, the trials generated few concerns of applicability. Several other scoring systems for assessing the risk of bias in both observational and interventional studies have been developed, e.g. the GRADE method [32]. We used the QUADAS tool as this has recently been validated [33] by three reviewers independently rating the quality of 30 studies and found a final consensus rating of $91 \%, 90 \%$ and $85 \%$. They found the weaknesses of the QUADAS to be in the items uninterpretable test results and withdrawals.

Another component of the observed heterogeneity lies in the definition of FN, several different combinations of criteria have been used. Von Lilienfeld-Toal and colleagues [24] defined neutropenia as an absolute leucocyte count $<1.0$ cells $/ \mathrm{mm}^{3}$ while Kim et al. [27] defined neutropenia as a neutrofil count $<0.5$ cells $/ \mathrm{mm}^{3}$ or a count of 1 cells $/ \mathrm{mm}^{3}$ with a predicted decrease to $<0.5$ cells/ $\mathrm{mm}^{3}$. The remaining studies all used a neutrofil count of $<0.5$ cells $/ \mathrm{mm}^{3}$. Two studies $[19,24]$ accepted a single record of fever above $38^{\circ} \mathrm{C}$ as criteria for enrollment while the majority used either a single temperature spike of $38.3^{\circ} \mathrm{C}-38.5^{\circ} \mathrm{C}$ or several readings of fever above $38.0^{\circ} \mathrm{C}$ over various predefined periods of time. One study [26] only includes the neutrofil count in defin- ing FN. We hypothesize that the depth and duration of the neutropenia and the course of the temperature curve may affect the endogenous synthesis of the infectious biomarkers. An additional limitation to our review is the risk of publication bias, a well described tendency to publish reports demonstrating high diagnostic accuracy rather than studies failing to show an adequate effect $[34,35]$.

In $2008 \mathrm{Sakr}$ et al. [17] reviewed the available literature exploring the role of PCT in FN by analyzing the results from 30 trials involving infants, children and adults including patients receiving high dose chemotherapy supported by stem cell transplantation. They concluded that PCT may be a useable tool in the management of FN, but due to small number of patients enrolled in the trials and heterogeneity of both study population and the reference standard, a precise role of PCT remained unclear. We have updated the review of the existing literature and applied a more specific set of criteria for in and exclusion. Data suggest that adults and children with FN vary in the natural history of the infection and outcome [36] which needs to be taken into consideration in a systematic review.

In non-neutropenic medical patients suffering from suspected lower respiratory tract infections, several randomized controlled trials have demonstrated the safety and effectiveness of a PCT guided treatment algorithm being able to reduce initial antibiotic prescription by $40 \%-50 \%$ without adversely affecting the clinical outcome, as summarized and validated in a recent multicenter study by the ProREAL study team [37]. In handling FN there is no consensus on the optimal duration of antimicrobial therapy, high risk patients with acute leuke- 
mia might require antibiotics for several weeks, while in other cases antibiotics can cease following resolution of fever or recovery of the neutrofils. Due to the risk of overuse of antibiotic and development of drug resistance together with potential side effects and general health costs, it is desirable to reduce the antibiotic therapy provided this can be safely executed [38,39]. In contrast to non-neutropenic medical patients, a low level of evidence exists regarding the use of PCT guided antibiotic treatment in the neutropenic population. No randomized controlled trials have been performed and, as shown in our review, the observational studies vary in the methodological quality and often enroll a small number of patients. Despite all limitations PCT adds new diagnostic information to the standard approach to $\mathrm{FN}$ and might help risk stratifying patients with $\mathrm{FN}$, selecting patients who are at low risk of infection and could be handled as outpatient and benefit from less intensive antibiotics.

In conclusion, we have systematically reviewed the literature for all existing studies examining the diagnostic accuracy of PCT as a marker of infection in FN in adult cancer patients and found only 9 studies meeting our predefined criteria for in and exclusion. Both sensitivity and specificity had a broad range, with the sensitivity ranging from $42 \%$ to $72 \%$ and the specificity ranging from $64 \%$ to $89 \%$. As pointed out above, substantial heterogeneity was evident in quality appraisal both regarding study design, definitions of reference standard and patient population. The sources of the variability may account for some of the reported differences in the diagnostic accuracy reported across the studies. We propose PCT remains an interesting object for further investigation in the neutropenic population as the current level of evidence in the literature does not support a place in the standard of care of FN.

\section{ACKNOWLEDGEMENTS}

The staff at the University Library at Aarhus University is greatly appreciated for an invaluable assistance in the literature search.

\section{REFERENCES}

[1] Maruna, P., Nedelnikova, K. and Gürlich, R. (2000) Physiology and genetics of procalcitonin. Physiol Research, 49, S57-S61.

[2] Meisner, M. (2002) Pathobiochemistry and clinical use of procalcitonin. Clinical Chemica Acta, 323, 17-29. doi:10.1016/S0009-8981(02)00101-8

[3] Dandona, P., Nix, D., Wilson, M.F., et al. (1994) Procalcitonin increase after endotoxin injection in normal subjects. The Journal of Clinical Endocrinology \& Metabolism, 79, 1605-1608. doi:10.1210/jc.79.6.1605

[4] Gabay, C. and Kushner, I. (1999) Acute-phase proteins and other systemic responses to inflammation. The New England Journal of Medicine, 340, 448-454.

doi:10.1056/NEJM199902113400607

[5] Assicot, M., Gendrel, D., et al. (1993) High serum procalcitonin cencentration in patients with sepsis and infection. Lancet, 341, 515-518.

[6] Schneider, H.-G. and Lam, Q.T. (2007) Procalcitonin for the clinical laboratory, a review. Pathology, 39, 383-390. doi:10.1080/00313020701444564

[7] Simon, L., Gauvin, F., et al. (2004) Serum procalcitonin and C-reactive protein levels as markers of bacterial infection, a systematic review and meta-analysis. Clinical Infectious Diseases, 39, 206-217. doi:10.1086/421997

[8] Tang, B. and Eslick, G. (2007) Accuracy of procalcitonin for sepsis diagnosed in the critically ill patients, systematic review and meta-analysis. The Lancet Infectious Diseases, 7, 210-217. doi:10.1016/S1473-3099(07)70052-X

[9] Al-Nawas, B. and Shah, P.M. (1996) Procalcitonin in patients with and without immunosuppression and sepsis. Infection, 24, 30-32. doi:10.1007/BF01713044

[10] Marti, F. and Cullen, M.H. (2009) Management of febrile neutropenia, ESMO clinical recommendations. Annals of Oncology, 20, 166-169. doi:10.1093/annonc/mdp163

[11] Schwenkglenks, M., Jackish, C., Constenla, M., et al. (2006) Neutropenic event risk and impaired chemotherapy delivery in 6 european audits of breast cancer treatment. Support Care Cancer, 14, 901-909. doi:10.1007/s00520-006-0034-9

[12] Chang, J. (2000) Chemotherapy dose reduction and delay in clinical practice. Evaluating the risk to patient outcome in adjuvant chemotherapy for breast cancer. European Journal of Cancer, 36, S11-S14. doi:10.1016/S0959-8049(99)00259-2

[13] Elting, L.S., Rubenstein, E.B., et al. (1997) Outcomes of bacteremia in patients with cancer and neutropenia, observations from two decades of epidemiological and clinical trials. Clinical Infectious Diseases, 25, 247-59. doi: $10.1086 / 514550$

[14] Schüttrumpf, S., Binder, L., et al. (2003) Procalcitonin, a useful discriminator between febrile conditions of different origin in hemato-oncological patients. Annals of $\mathrm{He}-$ matology, 82, 98-103.

[15] Rintala, E. (1994) Incidence and clinical significance of positive blood cultures in febrile episodes of patients with hematological malignancies. Scandinavian Journal of Infectious Diseases, 26, 77-84. doi:10.3109/00365549409008594

[16] Kim, D.Y., Lee, Y.-S., et al. (2011) The usefulness of procalcitonin and $\mathrm{C}$-reactive protein as early diagnostic markers of bacteremia in cancer patients with febrile neutropenia. Cancer Treatment and Research, 43, 176-180. doi:10.4143/crt.2011.43.3.176

[17] Sakr, Y,, Sponholz, C., et al. (2008) The role of procalcitonin in febrile neutropenic patients, review of the literature. Infection, 36, 396-407. doi:10.1007/s15010-008-7374-y

[18] Whiting, P.F., Rutjes, A.W.S., Westwood, M.E., et al. 
(2011) QUADAS-2, a revised tool for the diagnostic accuracy studies. Annals of Internal Medicine, 155, 529536.

[19] Ruokonen, E., Nousiainen, T., Pulkki, K., et al. (1999) Procalcitonin concentration in patients with neutropenic fever. European Journal of Clinical Microbiology \& Infectious Diseases, 18, 283-285. doi:10.1007/s100960050277

[20] Engel, A., Steinbach, G., Kern, P., et al. (1999) Diagnostic value of procalcitonin serum levels in neutropenic patients with fever, comparison with interleukin-8. Scandinavian Journal of Infectious Diseases, 31, 185-189. doi:10.1080/003655499750006254

[21] Giamarellos-Bourboulis, E.J., Grecka, P., Poulakou, G., et al. (2001) Assessment of procalcitonin as a diagnostic marker of underlying infection in patients with febrile neutropenia. Clinical Infectious Diseases, 32, 1718-1725. doi:10.1086/320744

[22] Jimeno, A., Garcia-Velasco, A., del Val, O., et al. (2004) Assessment of procalcitonin as a diagnostic and prognostic marker in patients with solid tumors and febrile neutropenia. Cancer, 100, 2462-2469. doi:10.1002/cncr.20275

[23] Giamarellou, H., Giamarellos-Bourboulis, E.J., Repoussis, P., et al. (2004) Potential use of procalcitonin as a diagnostic criterion in febrile neutropenia, experience from a multicentre study. Clinical Microbiology and Infection, 10, 628-633. doi:10.1111/j.1469-0691.2004.00883.x

[24] Lilienfeld-Toal, M.V., Dietrich, M.P., Glasmacher, A., et al. (2004) Markers of bacteremia in febrile neutropenic patients with hematological malignancies, procalcitonin and IL-6 are more reliable than C-reactive protein. European Journal of Clinical Microbiology \& Infectious Diseases, 23, 539-544. doi:10.1007/s10096-004-1156-y

[25] Ahn, S., Lee, Y.-S., Chun, Y.H., et al. (2011) Predictive factors of bacteraemia in low-risk patients with febrile neutropenia. Emergency Medicine Journal, 29, 715-719.

[26] Gac, A.-C., Parienti, J.-J., Chantepie, S., et al. (2011) Dynamics of procalcitonin and bacteremia in neutropenic adults with acute myeloid leukemia. Leukemia Research, 35, 1294-1296. doi:10.1016/j.leukres.2011.05.035

[27] Kim, D.Y., Lee, Y.-S., Ahn, S., et al. (2011) The usefulness of procalcitonin and C-reactive protein as early diagnostic markers of bacteremia in cancer patientswith febrile neutropenia. Cancer Research and Treatment, 43, 176-180. doi:10.4143/crt.2011.43.3.176

[28] Rapoport, B.L. (2011) Management of the cancer patient with infection and neutropenia. Seminars in Oncology, 38, 424-430. doi:10.1053/j.seminoncol.2011.03.013

[29] Lyman, G., Michels, S., Reynolds, M., et al. (2010) Risk of mortality in patients with cancer who experience febrile neutropenia. Cancer, 1, 5555-5563.

[30] Schneider, H.-G. and Lam, Q.T. (2007) Procalcitonin for the clinical laboratory, a review. Pathology, 39, 383-390. doi:10.1080/00313020701444564

[31] Al-Ahwal, M., Al-Sayws, F. and Johar, I. (2005) Febrile neutronpenia comparison between solid tumors and hematological malignincies. Arab Medical Journal, 4, 4-7.

[32] Guyatt, G., Oxman, A., Vist, G., et al. (2008) What is quality of evidence" and why is it important to clinicians? British Medical Journal, 336, 995-998. doi:10.1136/bmj.39490.551019.BE

[33] Whiting, P., Weswood, M., Rutjes, A., et al. (2006) Evaluation of QUADAS, a tool for the quality assessment of diagnostic accuracy studies. BMC Medical Research Methodology, 2006, 6, 9. doi:10.1186/1471-2288-6-9

[34] Knudsen, T.B. and Kristiansen, T.B. (2005) Issues pertaining to data extraction and classification and publication bias in meta analysis of the diagnostic accuracy of markers of bacterial infection. Clinical Infectious Diseases, 40, 1372-1373. doi:10.1086/429507

[35] Whiting, P., Rutjes, A.W.S., Reitsma, J.B., et al. (2004) Sources of variation and bias in studies of diagnostic accuracy. Annals of Internal Medicine, 140, 189-202.

[36] Hann, I., Viscoli, C., Paesmans, M., et al. (1997) A comparison of outcome from febrile neutropenic episodes in children compared with adults, results from four EORTC studies. British Journal of Haematology, 99, 580-588. doi:10.1046/j.1365-2141.1997.4453255.X

[37] Albrich, W.C., Dusemund, F., Bucher, B., et al. (2012) Effectiveness and safety of procalcitonin-guided antibiotic therapy in lower respiratory tract infections in "real life". Archives of Internal Medicine, 172, 715-722. doi:10.1001/archinternmed.2012.770

[38] Hughes, W.T., Armstrong, D., Bodey, G.P., et al. (2002) Guidelines for the use of antimicrobial agents in neutronpenic patients with cancer. Clinical Infectious Diseases, 34, 730-751. doi:10.1086/339215

[39] Link, H., Bohme, A., Cornely, O.A., et al. (2003) Antimicrobial therapy of unexplained fever in neutropenic patients-Guidelines of the infectious disease working party of the german society of hematology and oncology. Annals of Hematology, 82, S105-S117. 